\title{
Advanced exergy analysis of a R744 booster refrigeration system with parallel compression
}

\author{
Gullo, Paride; Elmegaard, Brian; Cortella, Giovanni
}

Published in:

Energy

Link to article, DOI:

10.1016/j.energy.2016.04.043

Publication date:

2016

Document Version

Peer reviewed version

Link back to DTU Orbit

Citation (APA):

Gullo, P., Elmegaard, B., \& Cortella, G. (2016). Advanced exergy analysis of a R744 booster refrigeration system with parallel compression. Energy, 107, 562-571. https://doi.org/10.1016/j.energy.2016.04.043

\section{General rights}

Copyright and moral rights for the publications made accessible in the public portal are retained by the authors and/or other copyright owners and it is a condition of accessing publications that users recognise and abide by the legal requirements associated with these rights.

- Users may download and print one copy of any publication from the public portal for the purpose of private study or research.

- You may not further distribute the material or use it for any profit-making activity or commercial gain

- You may freely distribute the URL identifying the publication in the public portal

If you believe that this document breaches copyright please contact us providing details, and we will remove access to the work immediately and investigate your claim 


\title{
Advanced Exergy Analysis of a R744 Booster Refrigeration System with Parallel Compression
}

\author{
Paride Gullo $^{a}$, Brian Elmegaard ${ }^{b}$ and Giovanni Cortella \\ ${ }^{a}$ University of Udine, DPIA, via delle Scienze 206, 33100 Udine, Italy, gullo.paride@spes.uniud.it \\ ${ }^{b}$ DTU Technical University of Denmark, Department of Mechanical Engineering, Nils Koppels Allé 403, \\ 2800 Kgs. Lyngby, Denmark, be@mek.dtu.dk \\ ${ }^{c}$ University of Udine, DPIA, via delle Scienze 206, 33100 Udine, Italy, giovanni.cortella@uniud.it
}

\section{Corresponding author: \\ - Paride Gullo \\ - Email address: qullo.paride@spes.uniud.it \\ - Tel: +390432 558022 \\ - Fax: +390432558027}

\begin{abstract}
:
In this paper, the advanced exergy analysis was applied to a R744 booster refrigeration system with parallel compression taking into account the design external temperatures of $25^{\circ} \mathrm{C}$ and $35^{\circ} \mathrm{C}$, as well as the operating conditions of a conventional European supermarket. The global efficiencies of all the chosen compressors were extrapolated from some manufactures' data and appropriated optimization procedures of the performance of the investigated solution were implemented.

According to the results associated with the conventional exergy evaluation, the gas cooler/condenser, the high stage (HS) compressor and the medium temperature (MT) display cabinet exhibited the highest enhancement potential. The further splitting of their corresponding exergy destruction rates into their different parts and the following assessment of the interactions among the components allowed figuring out the real achievable improvements. The avoidable irreversibilities of the HS compressor and that of the MT evaporator were mainly and completely endogenous, respectively. On the other hand, the gas cooler/condenser could be predominantly improved by decreasing the inefficiencies of the MT evaporator. As regards the auxiliary compressor, large enhancements were attainable through the drop in the irreversibilities occurring in the remaining components.
\end{abstract}

\section{Keywords:}

Advanced Exergetic Analysis, $\mathrm{CO}_{2}$, Exergy Destruction, Parallel Compression, Supermarket, Transcritical Refrigeration System.

\section{Nomenclature}

COP Coefficient of Performance

$\dot{E} \quad$ Exergy rate $[\mathrm{kW}]$

$e \quad$ Exergy per unit of mass $\left[\mathrm{kJ}^{\prime} \cdot \mathrm{kg}^{-1}\right]$

GWP Global Warming Potential $\left[\mathrm{kg}_{\mathrm{CO}_{2}} \cdot \mathrm{kg}_{\text {refrigerant }}^{-1}\right]$

$h \quad$ Enthalpy per unit of mass $\left[\mathrm{kJ} \cdot \mathrm{kg}^{-1}\right]$

$m$ Mass flow rate $\left[\mathrm{kg} \cdot \mathrm{s}^{-1}\right]$

$p \quad$ Pressure [bar]

$s \quad$ Entropy per unit of mass $\left[\mathrm{kJ} \cdot \mathrm{kg}^{-1} \cdot \mathrm{K}^{-1}\right]$ 
$t \quad$ Temperature $\left[{ }^{\circ} \mathrm{C}\right]$

$y^{*} \quad$ Exergy destruction rate

Abbreviations

AUX Auxiliary compressor

compr Compressor

EES Engineering Equation Solver

evap Evaporator

exp Expansion valve

$G C \quad$ Air cooled gas cooler/condenser

HP High pressure

HS High stage

LS Low stage

LT Low temperature

MT Medium temperature

$V B \quad$ Vapour by-pass

\section{Greek symbols}

$\Delta \quad$ Difference

$\eta \quad$ Efficiency

$\chi \quad$ Flash gas mass flow rate drawn by the auxiliary compressor $\left[\mathrm{kg} \cdot \mathrm{s}^{-1}\right]$

Subscripts and superscripts

\begin{tabular}{ll} 
appr & Approach \\
aux & Auxiliary compressor \\
AV & Avoidable \\
compr & Compressor \\
$D$ & Destruction \\
el & Electrical \\
EN & Endogenous \\
evap & Evaporator \\
EX & Exogenous \\
exp & Expansion valve \\
ext & External \\
$g c$ & Air cooled gas cooler/condenser \\
glob & Global \\
$H P$ & High pressure \\
$H S$ & High stage \\
int & Intermediate \\
isen & Isentropic \\
$k$ & $k$-th component of the system \\
$L$ & Loss \\
$L T$ & Low temperature \\
$M T$ & Medium temperature \\
$M X$ & Mexogenous \\
\hline
\end{tabular}




$\begin{array}{ll}\text { out } & \text { Outlet } \\ P H & \text { Physical } \\ p p & \text { Pinch point } \\ r & r \text {-th component of the system } \\ \text { tot } & \text { Total } \\ \text { UN } & \text { Unavoidable }\end{array}$

\section{Introduction}

The raising awareness of the environmental preservation and the strict regulation adopted in Europe on the subject of refrigeration have been promoting the use of natural and synthetic refrigerants with low Global Warming Potential (GWP) in all the sectors. Commercial refrigeration features both high energy consumption, which is accountable for the indirect production of environmentally harmful gases, and large working fluid leakages into the atmosphere, which directly contribute to the global warming effect. Carbon dioxide (R744) is a natural refrigerant which can almost completely work out the issue associated with the direct emissions. Furthermore, it is inexpensive, non-toxic, nonflammable and has good thermo-physical characteristics. Thanks to its great performance in cold climate locations, $\mathrm{CO}_{2}$ is capable of outperforming high GWP refrigerants as well as of reducing greenhouse gases emissions significantly. On the other hand, the performance of R744 is more depending on the heat sink temperature than in the case of the other working fluids due to its low critical temperature $\left(30.98{ }^{\circ} \mathrm{C}\right)$. This causes the occurrence of transcritical operations and consequently large temperature lift values, which penalise the $\mathrm{CO}_{2}$ machines efficiency considerably with rise in cooling medium temperature. As shown by Cavallini and Zilio (2007), in these running modes an optimal heat rejection pressure, which maximizes the Coefficient of Performance (COP), has to be identified as a function of the gas cooler exit temperature.

A large number of researchers have focused on the evaluation of the most suitable configuration for being adopted in warm climates in order to achieve similar consumption to the one exhibited by the systems using conventional refrigerants. The advanced exergy analysis represents one of the most appropriate design tools and, to this end, its application to a $\mathrm{CO}_{2}$ refrigeration system operating at high outdoor temperatures could be significantly helpful. Such type of evaluation allows identifying, locating and quantifying the irreversibilities occurring in the system under investigation. It can further evaluate the irreversibilities occurring in an individual component and the ones due to the interactions among the components.

The adoption of an auxiliary compressor allows enhancing the performance of a R744 conventional system markedly, as proved by Gullo et al. (2016), Gullo et al. (2015), Polzot et al. (2015), Minetto et al. (2005) and Bell (2004). From the thermodynamic point of view, the parallel compression enables achieving a remarkable drop in the exergy destruction rate associated with the throttling valve located upstream of the liquid receiver (Gullo et al., 2015). Such component is characterized by the highest irreversibilities in a R744 transcritical refrigeration system (Fazelpour and Morosuk, 2014). Besides proving the good effectiveness of the configuration with the auxiliary compressor, Sarkar and Agrawal (2010) demonstrated that the performance of the whole system is influenced by the intermediate pressure which, in turn, is affected by the value of the evaporating temperature. The existence of an optimal intermediate pressure was also proved by Bell (2004), Minetto et al. (2005) and Chiarello et al. (2010). On the other hand, the vapour mass flow rate $(\chi)$ compressed by means of the auxiliary compressor is an additional independent variable for the optimization procedure of such system (Gullo et al., 2016). 
In this paper, the intermediate pressure and $\chi$ were optimized for both the conventional exergy analysis and the advanced one.

The implementation of the advanced exergy analysis to a refrigeration system was carried out by Morosuk et al. (2012) to evaluate the potential improvements reachable by a Voorhees refrigerating machine. As a main result, the authors underlined that the enhancement of the system can be accomplished by reducing the inefficiencies taking place in the evaporator.

Chen et al. (2015) fulfilled a conventional and an advanced exergy analysis of an ejector refrigeration system. The authors showed that the ejector itself is accountable for more than $50 \%$ of the irreversibilities occurring in the system. Furthermore, a drop in the condenser temperature difference would lead to a decrement in the inefficiencies of the heat exchanger itself and to those of the overall system.

Gungor et al. (2013) investigated the unavoidable and avoidable irreversibilities associated with the components of a gas engine heat pump. Erbay and Hepbasli (2014) demonstrated that the performance enhancement of a ground-source heat pump drying system can be attained through the improvement of the condenser. Açikkalp et al. (2014) suggested paying close attention to the turbo air compressor of a trigeneration solution.

The aim of this paper is to evaluate the possible thermodynamic improvements that a R744 booster supermarket refrigeration system with parallel compression can accomplish by employing the advanced exergy analysis. To the best of the authors' knowledge, such evaluation has never applied to any transcritical $\mathrm{CO}_{2}$ refrigeration systems. The description of the system under consideration and the most important notions of both the conventional exergy analysis and the advanced one are given in Section 2. The main outcomes are then summed up and discussed in Section 3 and in Section 4, respectively. The conclusion are thus provided in Section 5.

\section{Methodology}

\subsection{System description}

The R744 booster refrigeration system investigated in this study is schematized in Fig. 1. This system serves both the chilled food cabinets and the frozen food counters simultaneously since it is intended for commercial applications. Four different pressure levels can be identified (from the highest to the lowest one): the high pressure in the gas cooler/condenser, the intermediate pressure in the liquid receiver, the medium pressure in the MT evaporators and the low pressure in the evaporators at low temperature (LT). This system is different from a conventional $\mathrm{CO}_{2}$ booster refrigeration system because of the presence of an auxiliary compressor. Such component is used to draw a part or the total amount of the so-called "flash gas", i.e. the vapour which is generated at the intermediate pressure after the expansion in the high pressure (HP) expansion valve. In a conventional system, such vapour is completely throttled to the medium pressure and then it is mixed with both the refrigerant exiting the MT display cabinets and the one discharged by the low stage (LS) compressor. 


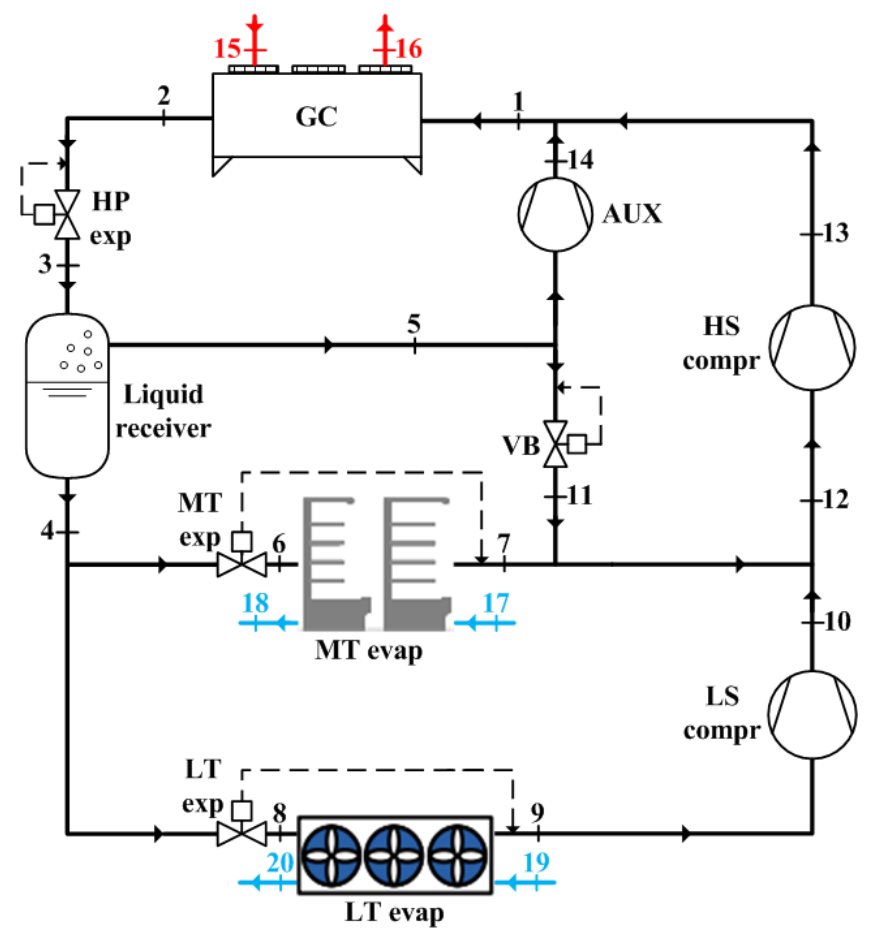

Fig. 1 Schematic of a R744 booster refrigeration system with parallel compression.

The selected operating conditions, which are summarized in Table 1, are typical of a European supermarket (Gullo et al., 2016). The internal superheating (Table 1) is imposed by means of the thermostatic valve located upstream of the corresponding evaporator. On the other hand, due to the length of the suction lines in supermarket applications and to the presence of heat sources along the path to the compressors, the refrigerant is usually additionally superheated. This phenomenon was considered by further increasing its temperature by 5 K (Gullo et al., 2016).

\section{Table 1}

Operating conditions of the investigated system.

\begin{tabular}{ccc}
\hline MT load & 97 & $\mathrm{~kW}$ \\
LT load & 18 & $\mathrm{~kW}$ \\
Medium evaporating temperature & -10 & ${ }^{\circ} \mathrm{C}$ \\
Low evaporating temperature & -35 & ${ }^{\circ} \mathrm{C}$ \\
Internal superheating & 5 & $\mathrm{~K}$ \\
Superheating in the suction line & 5 & $\mathrm{~K}$ \\
Gas cooler/condenser fan power & 4.5 & $\mathrm{~kW}_{\mathrm{el}}$ \\
MT evaporator fans, lights, defrost & 10 & $\mathrm{~kW}_{\mathrm{el}}$ \\
LT evaporator fans, lights, defrost & 4 & $\mathrm{~kW}_{\mathrm{el}}$ \\
\hline
\end{tabular}

The numerical model was implemented at steady state by using Engineering Equation Solver (EES) (F-Chart Software, 2015a) and assuming negligible pressure drop.

Table 2 shows the global efficiencies of the $\mathrm{CO}_{2}$ compressors derived from BITZER Software (BITZER, 2015) as a function of the pressure ratio. As defined by Gullo et al. (2016), the global 
efficiency of a compressor is the ratio of the power input calculated in isentropic conditions to the one indicated by the manufacturer at the same boundary conditions.

\section{Table 2}

Global efficiencies ( $\left.\eta_{\text {glob }}\right)$ of the selected compressors in the actual conditions.

\begin{tabular}{ccc}
\hline & $\mathrm{t}_{\mathrm{ext}}=25^{\circ} \mathrm{C}$ & $\mathrm{t}_{\mathrm{ext}}=35^{\circ} \mathrm{C}$ \\
\hline Auxiliary compressor & 0.670 & 0.690 \\
High stage compressor & 0.672 & 0.657 \\
Low stage compressor & 0.674 & 0.674 \\
\hline
\end{tabular}

As showed by Gullo et al. (2016), four operating zones (Fig. 2) can be identified in a transcritical $\mathrm{CO}_{2}$ supermarket refrigeration cycle. In Fig. 2, Zone I denotes the subcritical running modes in which the condensing temperature was independent of the external temperature and maintained equal to a minimum value (i.e. $9^{\circ} \mathrm{C}$ ). The reaching of Zone II was governed by both the outdoor temperature and the approach temperature of the condenser. It is worth remarking that the approach temperature of a heat exchanger is defined as the difference of the outgoing hot fluid temperature and the ingoing cold fluid temperature. Considering a $\Delta \mathrm{T}_{\text {appr,gc }}$ of $3 \mathrm{~K}$ and a degree of subcooling of $2 \mathrm{~K}$ for the investigated solution, these operating conditions started taking place at outdoor temperatures above $4{ }^{\circ} \mathrm{C}$. In these running modes, the temperature of the R744 leaving the condenser could be computed as the sum of text and $\Delta \mathrm{T}_{\text {appr,gc. }}$ A transition zone (Zone III in Fig. 2) has to be set to allow a $\mathrm{CO}_{2}$ refrigerating unit to move from the subcritical operations to the transcritical ones gradually. Two couples of values heat rejection pressure-temperature of the $\mathrm{CO}_{2}$ exiting the gas cooler/condenser have to be chosen to define the upper limit (point B in Fig. 2) and the lower one (point A in Fig. 2) of such operating zone. The point A represented the thermodynamic state described by the condensing pressure and the outlet temperature of the refrigerant leaving the condenser of 60.03 bar and $20^{\circ} \mathrm{C}$, respectively. The point $\mathrm{B}$ defined the thermodynamic state identified by the heat rejection pressure and the temperature of the R744 coming out of the gas cooler equal to 75 bar and $29^{\circ} \mathrm{C}$, respectively. Furthermore, the approach temperature of the high pressure heat exchanger was progressively brought from $3 \mathrm{~K}$ (point A in Fig. 2) down to $2 \mathrm{~K}$ (point B in Fig. 2). In Zone III, the system was thus run along the operating conditions denoted by the segment A-B in Fig. 2 by following the correlations below:

$$
\begin{gathered}
t_{\text {out }, \mathrm{gc}}=0.9 \cdot t_{\mathrm{ext}}+4.7 \\
p_{g c}=1.6633 \cdot t_{\text {out }, g c}+26.763
\end{gathered}
$$

At outdoor temperatures above $27{ }^{\circ} \mathrm{C}$, transcritical conditions (Zone IV) occurred and, as aforementioned, an optimal high pressure was assessed as a function of the gas cooler exit temperature (Cavallini and Zilio, 2007). 


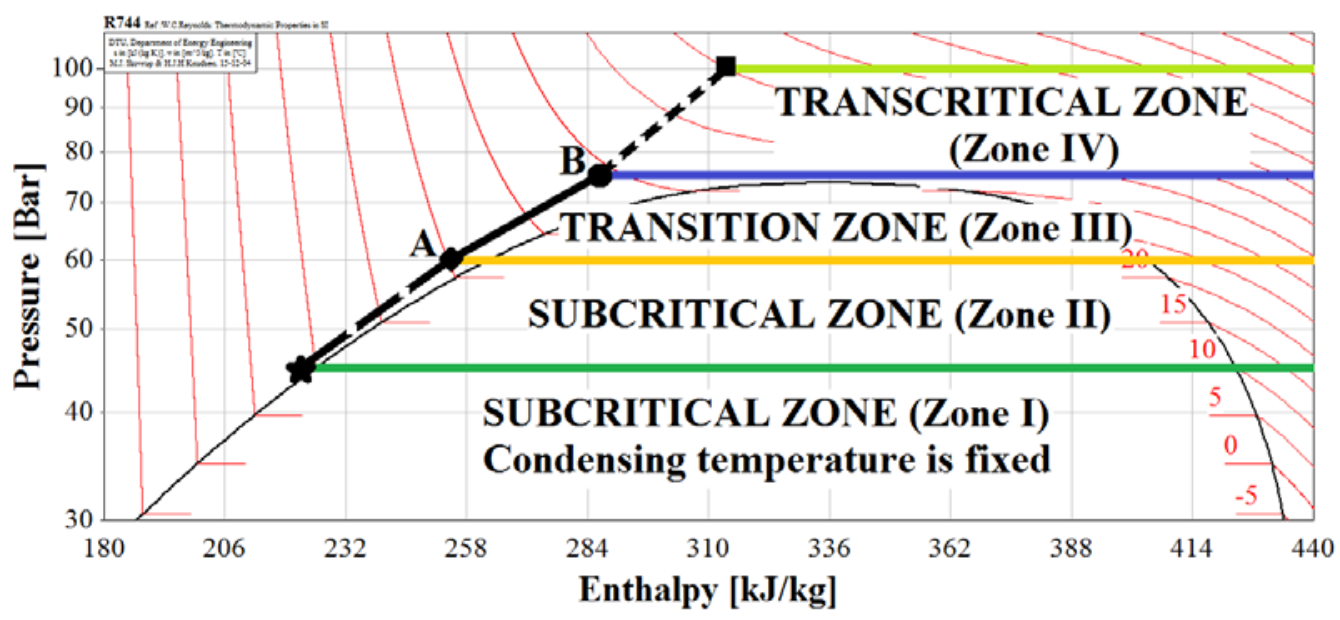

Fig. 2 Definition of the operating zones for the investigated system (Gullo et al., 2016).

In this paper, the design outdoor temperatures of $25^{\circ} \mathrm{C}$ and $35^{\circ} \mathrm{C}$ were taken into account, which referred to a transition operating condition and a transcritical one, respectively.

As already mentioned, the system under consideration has to be optimized as a function of both $\chi$ and the intermediate pressure in transition conditions in order to minimize the total energy consumption. As soon as transcritical conditions take place, the gas cooler pressure becomes an additional independent variable. In this study, the optimization process was based on the implementation of the DIRECT algorithm Method (F-Chart Software, 2015b). Neither the details regarding the existence and the computation procedure of the optimal heat rejection pressure nor the ones of the optimal intermediate pressure were included since they have already been thoroughly explained by many researchers (Sawalha, 2008; Ge and Tassou, 2011; Minetto et al., 2005; Chiarello et al., 2010). Furthermore, the specific methodology applied to this investigation was comprehensively described by Gullo et al. (2016), whose outcomes are summarized in Table 3.

\section{Table 3}

Thermodynamic variables derived from the optimization procedures at the design outdoor temperatures of $25^{\circ} \mathrm{C}$ and $35^{\circ} \mathrm{C}$ in actual conditions (Gullo et al., 2016).

\begin{tabular}{ccc}
\hline Parameter & $\mathrm{t}_{\text {ext }}=25^{\circ} \mathrm{C}$ & $\mathrm{t}_{\text {ext }}=35{ }^{\circ} \mathrm{C}$ \\
\hline$\chi\left[\mathrm{kg} \cdot \mathrm{s}^{-1}\right]$ & 0.235 (Optimized) & 0.467 (Optimized) \\
pgc $[\mathrm{bar}]$ & 72.00 (Not optimized) & 89.35 (Optimized) \\
pint $[\mathrm{bar}]$ & 41.63 (Optimized) & 48.21 (Optimized) \\
$\mathbf{\Delta} \mathbf{T}_{\text {appr,gc }}[\mathbf{K}]$ & 2.2 & 2.0 \\
\hline
\end{tabular}

\subsection{Exergy analysis}

\subsubsection{Conventional exergy analysis}

The exergy of a system is the maximum useful work obtainable by bringing the system under investigation into thermodynamic equilibrium with the surroundings. Both the conventional exergy analysis and the advanced one were carried out by evaluating the exergy rate balance at steady state (Moran et al., 2011) of each component of the chosen system. The outcomes obtained were based on the assumption that the chemical, kinetics and potential exergy contributions were not significant. 
The exergy destruction ratio is the ratio of the exergy destruction rate of the $k$-th component to the total exergy destruction rate of the overall system:

$$
y_{k}^{*}=\frac{\dot{E}_{D, k}}{\dot{E}_{D, t o t}}
$$

The following additional assumptions, along with those presented in Table 4, were made:

- an increment of $5{ }^{\circ} \mathrm{C}$ in the air temperature leaving the gas cooler was chosen;

- the pinch point temperature of the gas cooler/condenser was assumed to be coinciding with its corresponding approach one. For this reason, the high pressure values showed in Table 3 were kept constant in both the conducted analyses;

- the temperature and the pressure of the air flowing through both the evaporators were chosen in accordance with the values presented by Ommen and Elmegaard (2012);

- conforming to Ommen and Elmegaard (2012), the definition of the dead state does not affect the outcomes of the exergy analysis markedly.

\section{Table 4}

Additional parameters for the exergy analysis.

\begin{tabular}{ccc}
\hline Air pressure & 1.01 & $\mathrm{bar}$ \\
Dead state temperature & 25 & ${ }^{\circ} \mathrm{C}$ \\
Dead state pressure & 1.01 & $\mathrm{bar}$ \\
Temperature of air entering MT evaporator & 5 & ${ }^{\circ} \mathrm{C}$ \\
Temperature of air exiting MT evaporator & -5 & ${ }^{\circ} \mathrm{C}$ \\
Temperature of air entering LT evaporator & -18 & ${ }^{\circ} \mathrm{C}$ \\
Temperature of air exiting LT evaporator & -25 & ${ }^{\circ} \mathrm{C}$ \\
\hline
\end{tabular}

\subsubsection{Advanced exergy analysis}

\subsubsection{Avoidable and unavoidable exergy destruction}

The splitting of the destruction exergy into its avoidable and unavoidable parts reveals the real enhancements which the system under investigation can reach. In fact, the unavoidable exergy destruction $\left(\dot{E}_{D, k}^{U N}\right)$ of the component being considered represents the part of the irreversibilities which cannot be reduced due to technological and economic constraints (i.e. manufacturing methods, cost and availability of the materials). The designer's efforts thus have to be addressed to reduce the avoidable part $\left(\dot{E}_{D, k}^{A V}\right)$ (Morosuk et al., 2012; Morosuk and Tsatsaronis, 2009; Tsatsaronis and MoungHo, 2002).

$$
\dot{E}_{D, k}=\dot{E}_{D, k}^{U N}+\dot{E}_{D, k}^{A V}
$$

$\dot{E}_{D, k}^{U N}$ for the $k$-th component can be calculated by simulating a thermodynamic cycle in which only the unavoidable inefficiencies occur (Morosuk et al., 2012; Morosuk and Tsatsaronis, 2009). In this paper, this new cycle was based on the assumptions summarized in the third column of Table 5. 


\section{Table 5}

Assumptions made for the advanced exergy analysis.

\begin{tabular}{ccc}
\hline Compressors & $\eta_{\text {glob }}^{E N}=1.00$ & $\eta_{\text {glob }}^{U N}=0.94$ \\
Expansion valves & $\eta_{\text {isen }}^{E N}=1.00$ & - \\
Heat exchangers & $\Delta \mathrm{T}_{p p}^{E N}=0.00 \mathrm{~K}$ & $\Delta \mathrm{T}_{p p}^{U N}=0.50 \mathrm{~K}$ \\
\hline
\end{tabular}

Sarkar and Agrawal (2010) demonstrated that the optimal intermediate pressure of a transcritical R744 refrigeration system employing an auxiliary compressor is firstly affected by the evaporating temperature. In unavoidable conditions, both the display cabinets underwent an increment in the refrigerant evaporating temperature to achieve the value of $\Delta \mathrm{T}_{p p}^{U N}$ pointed out in Table 5 (Morosuk et al., 2012; Morosuk and Tsatsaronis, 2009). As a main consequence of this, new optimum values of both the intermediate pressure and $\chi$ had to be identified. This procedure was not applied in terms of optimal gas cooler pressure since $\Delta \mathrm{T}_{p p, g c}^{U N}$ coincided with $\Delta \mathrm{T}_{a p p r, g c}^{U N}$. The implemented optimization procedure was the same as the one applied in actual operating conditions and the outcomes obtained are summarized in Table 6.

\section{Table 6}

Results of the optimization procedure at the design outdoor temperatures of $25^{\circ} \mathrm{C}$ and $35{ }^{\circ} \mathrm{C}$ in unavoidable conditions.

\begin{tabular}{ccc}
\hline Parameter & $\mathrm{t}_{\mathrm{ext}}=25^{\circ} \mathrm{C}$ & $\mathrm{t}_{\mathrm{ext}}=35{ }^{\circ} \mathrm{C}$ \\
$\chi\left[\mathrm{kg} \cdot \mathrm{s}^{-1}\right]$ & 0.167 (Optimized) & 0.331 (Optimized) \\
pgc $[\mathrm{bar}]$ & 72 (Not optimized) & 89.35 (Optimized) \\
pint $[\mathrm{bar}]$ & 44.18 (Optimized) & 51.42 (Optimized) \\
\hline
\end{tabular}

\subsubsection{Endogenous and exogenous exergy destruction}

The inefficiencies which occur in the $k$-th component when it is operating with its actual efficiency and all the remaining components are operating in ideal conditions, represent its endogenous exergy destruction $\left(\dot{E}_{D, k}^{E N}\right)$. The exogenous exergy destruction within the $k$-th component $\left(\dot{E}_{D, k}^{E X}\right)$ is associated with the irreversibilities taking place in the remaining components (Morosuk et al., 2012; Morosuk and Tsatsaronis, 2009; Tsatsaronis, 2008).

$$
\dot{E}_{D, k}=\dot{E}_{D, k}^{E N}+\dot{E}_{D, k}^{E X}
$$

In the present study, $\dot{E}_{D, k}^{E N}$ of the $k$-th component was computed by assuming the operating conditions reported in the second column of Table 5 for the selected component and the actual running modes for the remaining components (Morosuk et al., 2012; Morosuk and Tsatsaronis, 2009). According to Table 5, the isentropic conditions embody the theoretical operating conditions of both the compressors and the expansion valves. As far as heat exchangers are concerned, their ideal conditions are accomplished by assuming a null value of their temperature difference between the two fluids since they cannot reach a unitary value of exergy efficiency.

An optimization procedure similar to the one applied in unavoidable conditions was implemented in endogenous conditions. The outcomes obtained are summed up in Table 7. 


\section{Table 7}

Results of the optimization procedure at the design outdoor temperatures of $25^{\circ} \mathrm{C}$ and $35{ }^{\circ} \mathrm{C}$ in endogenous conditions.

\begin{tabular}{ccc}
\hline Parameter & $\mathrm{t}_{\mathrm{ext}}=25^{\circ} \mathrm{C}$ & $\mathrm{t}_{\mathrm{ext}}=35^{\circ} \mathrm{C}$ \\
\hline$\chi\left[\mathrm{kg} \cdot \mathrm{s}^{-1}\right]$ & 0.127 (Optimized) & 0.236 (Optimized) \\
Pgc $[\mathrm{bar}]$ & 72.00 (Not optimized) & 89.35 (Optimized) \\
pint $[\mathrm{bar}]$ & 44.09 (Optimized) & 51.01 (Optimized) \\
\hline
\end{tabular}

\subsubsection{Combining the two splitting approaches}

The further splitting of the exergy destruction components provides the designers with significantly important information regarding the enhancement process to implement:

$$
\dot{E}_{D, k}=\dot{E}_{D, k}^{U N, E N}+\dot{E}_{D, k}^{U N, E X}+\dot{E}_{D, k}^{A V, E N}+\dot{E}_{D, k}^{A V, E X}
$$

The avoidable endogenous $\left(\dot{E}_{D, k}^{A V, E N}\right)$ and the avoidable exogenous exergy $\left(\dot{E}_{D, k}^{A V, E X}\right)$ destruction rates of the $k$-th component can be reduced by lowering the irreversibilities of the components themselves and by enhancing the efficiencies of the remaining components, respectively. On the contrary, the unavoidable endogenous $\left(\dot{E}_{D, k}^{U N, E N}\right)$ and the exogenous parts $\left(\dot{E}_{D, k}^{U N, E X}\right)$ of the exergy destruction of the $k$-th component cannot be decreased because of technological and economic constraints of the component itself and the ones associated with the other components, respectively (Morosuk et al., 2012; Morosuk and Tsatsaronis, 2009; Tsatsaronis, 2008).

A calculation procedure similar to that applied by Morosuk and Tsatsaronis (2009) was used in this paper to assess the values of $\dot{E}_{D}^{U N}$ and $\dot{E}_{D}^{U N, E N}$ in all the evaluated cases.

\subsubsection{Interactions among the components}

The mexogenous exergy destruction $\left(\dot{E}_{D, k}^{M X}\right)$ allows understanding the concurrent interaction among the component of the system under investigation. For the $k$-th component, it is evaluated as:

$$
\dot{E}_{D, k}^{M X}=\dot{E}_{D, k}^{E X}-\sum_{\substack{r=1 \\ r \neq k}}^{n} \dot{E}_{D, k}^{E X, r}
$$

$\sum_{\substack{r=1 \\ r \neq k}}^{n} \dot{E}_{D, k}^{E X, r}$ is the exogenous exergy destruction of the $k$-th component due to the irreversibilities which occur in the $r$-th component (Morosuk et al., 2012; Wang et al., 2012).

\section{Results}

\subsection{Results of the conventional exergy analysis}

Table 8 and Table 9 show temperature, pressure, mass flow rate, specific enthalpy, specific entropy and physical exergy at the design outdoor temperatures of $25{ }^{\circ} \mathrm{C}$ and $35{ }^{\circ} \mathrm{C}$ of the actual thermodynamic cycle. 
Table 8

State points for the thermodynamic cycle of the investigated solution operating in actual conditions at the design outdoor temperature of $25^{\circ} \mathrm{C}$.

\begin{tabular}{cccccccc}
\hline State point & Fluid & $\begin{array}{c}\mathrm{t} \\
{\left[{ }^{\circ} \mathrm{C}\right]}\end{array}$ & $\begin{array}{c}\mathrm{p} \\
{[\mathrm{bar}]}\end{array}$ & $\begin{array}{c}\dot{m} \\
{\left[\mathrm{~kg} \cdot \mathrm{s}^{-1}\right]}\end{array}$ & $\begin{array}{c}\mathrm{h} \\
{\left[\mathrm{kJ} \cdot \mathrm{kg}^{-1}\right]}\end{array}$ & $\begin{array}{c}\mathrm{s} \\
{\left[\mathrm{kJ} \cdot\left(\mathrm{kg}^{-1} \cdot \mathrm{K}^{-1}\right)\right]}\end{array}$ & $\begin{array}{c}e^{P H} \\
{\left[\mathrm{~kJ} \cdot \mathrm{kg}^{-1}\right]}\end{array}$ \\
\hline 1 & R744 & 89.2 & 72.00 & 0.809 & 511.8 & 1.999 & 226.10 \\
2 & R744 & 27.2 & 72.00 & 0.809 & 278.0 & 1.256 & 213.90 \\
3 & R744 & 6.9 & 41.63 & 0.809 & 278.0 & 1.277 & 207.70 \\
4 & R744 & 6.9 & 41.63 & 0.574 & 217.4 & 1.060 & 211.60 \\
5 & R744 & 6.9 & 41.63 & 0.235 & 425.9 & 1.805 & 198.10 \\
6 & R744 & -10.0 & 26.49 & 0.476 & 217.4 & 1.071 & 208.40 \\
7 & R744 & -5.0 & 26.49 & 0.476 & 442.3 & 1.926 & 178.50 \\
8 & R744 & -35.0 & 12.02 & 0.098 & 217.4 & 1.104 & 198.50 \\
9 & R744 & -30.0 & 12.02 & 0.098 & 441.6 & 2.045 & 142.10 \\
10 & R744 & 44.0 & 26.49 & 0.098 & 499.4 & 2.122 & 177.10 \\
11 & R744 & -10.0 & 26.49 & 0.001 & 425.9 & 1.863 & 180.60 \\
12 & R744 & 7.3 & 26.49 & 0.574 & 458.3 & 1.984 & 177.10 \\
13 & R744 & 103.0 & 72.00 & 0.574 & 529.7 & 2.048 & 229.50 \\
14 & R744 & 59.5 & 72.00 & 0.235 & 468.1 & 1.873 & 219.90 \\
15 & Air & 25.0 & 1.01 & 38.470 & 298.4 & 6.861 & 0.00 \\
16 & Air & 30.0 & 1.01 & 38.470 & 303.5 & 6.878 & 0.04 \\
17 & Air & 5.0 & 1.01 & 9.643 & 278.3 & 6.791 & 0.71 \\
18 & Air & -5.0 & 1.01 & 9.643 & 268.3 & 6.755 & 1.63 \\
19 & Air & -18.0 & 1.01 & 2.557 & 255.2 & 6.705 & 3.46 \\
20 & Air & -25.0 & 1.01 & 2.557 & 248.1 & 6.677 & 4.76 \\
\hline
\end{tabular}




\section{Table 9}

State points for the thermodynamic cycle of the investigated solution operating in actual conditions at the design outdoor temperature of $35^{\circ} \mathrm{C}$.

\begin{tabular}{cccccccc}
\hline State point & Fluid & $\begin{array}{c}\mathrm{t} \\
{\left[{ }^{\circ} \mathrm{C}\right]}\end{array}$ & $\begin{array}{c}\mathrm{p} \\
{[\mathrm{bar}]}\end{array}$ & $\begin{array}{c}\dot{m} \\
{\left[\mathrm{~kg} \cdot \mathrm{s}^{-1}\right]}\end{array}$ & $\begin{array}{c}\mathrm{h} \\
{\left[\mathrm{kJ} \cdot \mathrm{kg}^{-1}\right]}\end{array}$ & $\begin{array}{c}\mathrm{s} \\
{\left[\mathrm{kJ} \cdot\left(\mathrm{kg}^{-1} \cdot \mathrm{K}^{-1}\right)\right]}\end{array}$ & $\begin{array}{c}e^{P H} \\
{\left[\mathrm{~kJ} \cdot \mathrm{kg}^{-1}\right]}\end{array}$ \\
\hline 1 & R744 & 100.6 & 89.35 & 1.088 & 513.5 & 1.972 & 236.00 \\
2 & R744 & 37 & 89.35 & 1.088 & 313.9 & 1.365 & 217.40 \\
3 & R744 & 12.8 & 48.21 & 1.088 & 313.9 & 1.396 & 208.10 \\
4 & R744 & 12.8 & 48.21 & 0.618 & 233.5 & 1.114 & 211.60 \\
5 & R744 & 12.8 & 48.21 & 0.470 & 419.6 & 1.765 & 203.60 \\
6 & R744 & -10.0 & 26.49 & 0.512 & 233.5 & 1.132 & 206.20 \\
7 & R744 & -5.0 & 26.49 & 0.512 & 442.3 & 1.926 & 178.50 \\
8 & R744 & -35.0 & 12.02 & 0.106 & 233.5 & 1.172 & 194.50 \\
9 & R744 & -30.0 & 12.02 & 0.106 & 441.6 & 2.045 & 142.10 \\
10 & R744 & 44.0 & 26.49 & 0.106 & 499.4 & 2.122 & 177.10 \\
11 & R744 & -10.0 & 26.49 & 0.003 & 419.6 & 1.840 & 181.50 \\
12 & R744 & 7.2 & 26.49 & 0.621 & 458.2 & 1.983 & 177.10 \\
13 & R744 & 127.3 & 89.35 & 0.621 & 549.1 & 2.064 & 244.20 \\
14 & R744 & 70.8 & 89.35 & 0.467 & 466.2 & 1.839 & 228.10 \\
15 & Air & 35.0 & 1.01 & 44.030 & 308.5 & 6.894 & 0.17 \\
16 & Air & 40.0 & 1.01 & 44.030 & 313.5 & 6.911 & 0.37 \\
17 & Air & 5.0 & 1.01 & 9.643 & 278.3 & 6.791 & 0.71 \\
18 & Air & -5.0 & 1.01 & 9.643 & 268.3 & 6.755 & 1.63 \\
19 & Air & -18.0 & 1.01 & 2.557 & 255.2 & 6.705 & 3.46 \\
20 & Air & -25.0 & 1.01 & 2.557 & 248.1 & 6.677 & 4.76 \\
\hline
\end{tabular}

The large values of the air mass flow rates flowing through the high pressure heat exchanger presented in Table 9 and Table 10 can be justified by taking into account that very low values of the gas cooler/condenser approach temperature were selected.

Table 10 points out the results of the conventional exergy analysis calculated at both the chosen design temperatures. At the external temperature of $25{ }^{\circ} \mathrm{C}$, MT evap, GC and HS compr were respectively accountable for $26.5 \%(15.31 \mathrm{~kW}), 22.0 \%(12.69 \mathrm{~kW})$ and $18.9 \%(10.90 \mathrm{~kW})$ of the total irreversibilities occurring in the investigated system. Furthermore, the designer should also pay attention to LT evap (6.21 kW) and to HP exp (5.06 kW). On the other hand, GC presented the highest value of exergy destruction rate $(15.85 \mathrm{~kW})$, followed by MT evap $(15.30 \mathrm{~kW})$ and HS compr (14.86 $\mathrm{kW})$ at the outdoor temperature of $35{ }^{\circ} \mathrm{C}$. According to Fazelpour and Morosuk (2014), the contribution of HP exp to the total inefficiencies of a transcritical $\mathrm{CO}_{2}$ refrigeration unit is significant. In fact, $\dot{E}_{D, H P \text { exp }}$ in the evaluated system almost doubled because of the increment in the design temperature causing $8.8 \%$ at $25{ }^{\circ} \mathrm{C}$ and $13.5 \%$ at $35^{\circ} \mathrm{C}$ of $\dot{E}_{D, t o t}$. As regards the auxiliary compressor, it was responsible for low percentage contributions, which added up to $3.9 \%(2.24 \mathrm{~kW})$ and $5.8 \%$ $(4.33 \mathrm{~kW})$ at $25^{\circ} \mathrm{C}$ and $35^{\circ} \mathrm{C}$, respectively. The exergy destruction rates associated with VB could be totally neglected due to the irrelevant mass flow rate flowing through it. At $t_{\text {ext }}=25{ }^{\circ} \mathrm{C}$, the irreversibilities caused by the mixing point upstream of HS compr and those generated by the mixing 
point downstream of the compressors discharge amounted to $0.41 \mathrm{~kW}$ and to $0.54 \mathrm{~kW}$, respectively. These quantities were respectively equal to $0.44 \mathrm{~kW}$ and to $1.37 \mathrm{~kW}$ at the other selected design external temperature.

\section{Table 10}

Exergy parameters of the evaluated system at the design outdoor temperatures of $25^{\circ} \mathrm{C}$ and $35^{\circ} \mathrm{C}$.

\begin{tabular}{ccccccc}
\hline & \multicolumn{3}{c}{$\mathrm{t}_{\mathrm{ext}}=25^{\circ} \mathrm{C}$} & \multicolumn{3}{c}{$\mathrm{t}_{\mathrm{ext}}=35^{\circ} \mathrm{C}$} \\
\hline Component & $\dot{\mathrm{E}}_{\mathrm{D}}$ & $\dot{\mathrm{E}}_{\mathrm{L}}$ & $\mathrm{y}^{*}$ & $\dot{\mathrm{E}}_{\mathrm{D}}$ & $\dot{\mathrm{E}}_{\mathrm{L}}$ & $\mathrm{y}^{*}$ \\
& {$[\mathrm{~kW}]$} & {$[\mathrm{kW}]$} & & {$[\mathrm{kW}]$} & {$[\mathrm{kW}]$} & \\
\hline AUX & 2.24 & - & 0.039 & 4.33 & - & 0.058 \\
GC & 12.69 & 1.61 & 0.220 & 15.85 & 8.92 & 0.212 \\
HS compr & 10.90 & - & 0.189 & 14.86 & - & 0.199 \\
HP exp & 5.06 & - & 0.088 & 10.06 & - & 0.135 \\
LS compr & 1.62 & - & 0.028 & 1.75 & - & 0.023 \\
LT evap & 6.21 & - & 0.107 & 6.21 & - & 0.083 \\
LT exp & 1.28 & - & 0.022 & 1.81 & - & 0.024 \\
MT evap & 15.31 & - & 0.265 & 15.30 & - & 0.205 \\
MT exp & 1.54 & - & 0.027 & 2.73 & - & 0.037 \\
VB & 0.01 & - & 0.000 & 0.06 & - & 0.001 \\
Overall system & 57.80 & 1.61 & 1.000 & 74.76 & 8.92 & 1.000 \\
\hline
\end{tabular}

Furthermore, the low exergy efficiencies of the overall system at both the chosen outdoor temperatures suggested that remarkable enhancements could be carried out. In particular, values of exergy efficiency equal to 0.176 at $25^{\circ} \mathrm{C}$ and to 0.133 at $35^{\circ} \mathrm{C}$ were calculated. Interesting outcomes were found in terms of exergy losses. $\dot{E}_{L}$ of the chosen solution added up respectively to $1.61 \mathrm{~kW}$ at $25^{\circ} \mathrm{C}$ and $8.92 \mathrm{~kW}$ at $35^{\circ} \mathrm{C}$, growing by 5.6 times due to the increase in the design temperature. This result could be related to the rise in the air exergy content.

\subsection{Results of the advanced exergy analysis}

\subsubsection{Avoidable and unavoidable exergy destruction}

All the results of the advanced exergy analysis are summarized in Table 11 and Table 12 . With respect to the chosen system, the total preventable exergy destruction was accountable for over $58 \%$ of the total exergy destruction at both the selected design temperatures (Fig. 3a and Fig. 3b). 
(a) Design temperature $=25^{\circ} \mathrm{C}$

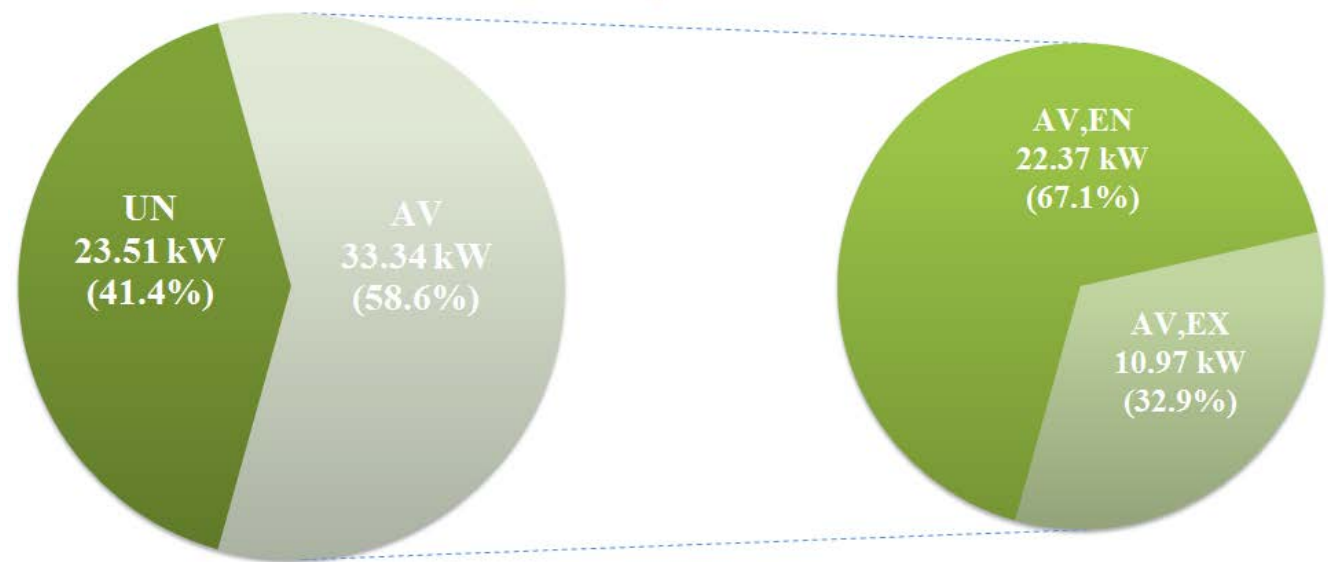

(b) Design temperature $=35^{\circ} \mathrm{C}$

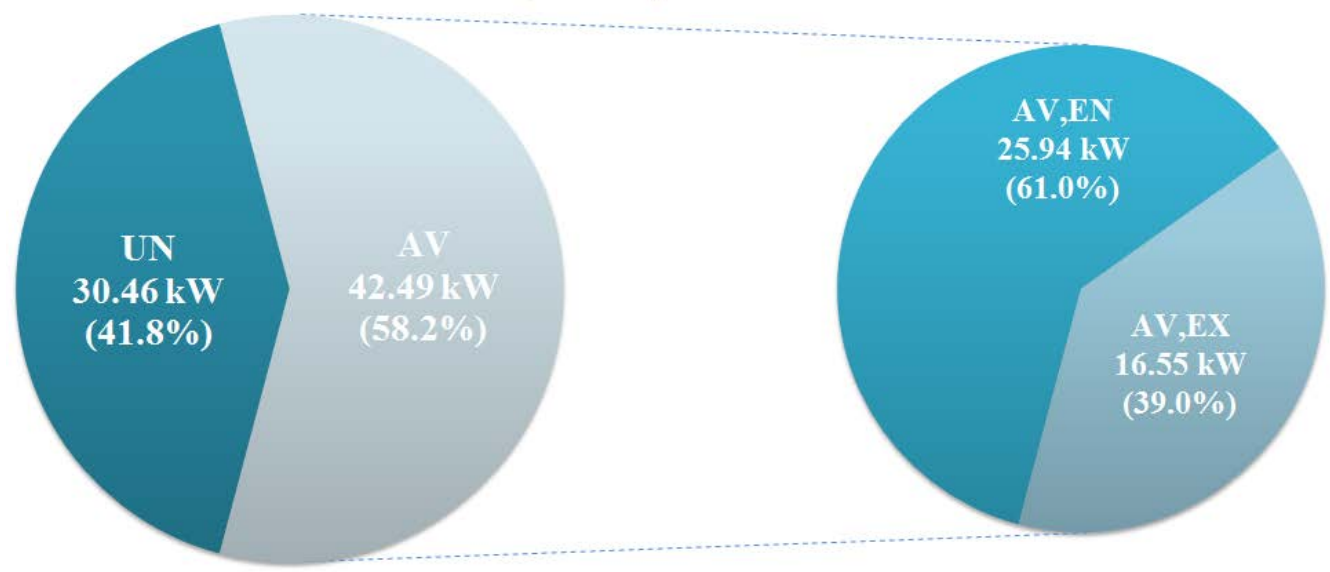

Fig. 3 Breakdown of the avoidable and unavoidable exergy destruction of the investigated system at text $=25^{\circ} \mathrm{C}$ (a) and at $t_{\text {ext }}=35^{\circ} \mathrm{C}$ (b).

All the evaporators had comparable values of $\dot{E}_{D}^{A V}$ to the ones associated with $\dot{E}_{D}^{U N}$ and the inefficiencies related to all the compressors were almost completely avoidable. On the contrary, MT exp, LT exp and HP exp were characterized by higher unavoidable exergy destruction rates beside their corresponding avoidable ones.

According to Fig. 4, the total preventable exergy destruction at text $=25^{\circ} \mathrm{C}$ and at text $=35^{\circ} \mathrm{C}$ was mainly due to the irreversibilities taking place in HS compr (29.2-31.3\%), GC (20.5-20.7\%) and MT evap (22.8-17.9\%). The contributions to $\dot{E}_{D, t o t}^{A V}$ on the part of AUX (6.2-9.3\%) and of LT evap (10.4$8.2 \%)$ at both the evaluated external temperatures, and that of HP exp $(7.4 \%)$ at $35{ }^{\circ} \mathrm{C}$, were also relevant. The increment in the avoidable exergy destruction rate due to the growth in the design temperature was noteworthy for AUX and HP exp and, secondly, for GC and HS compr. 


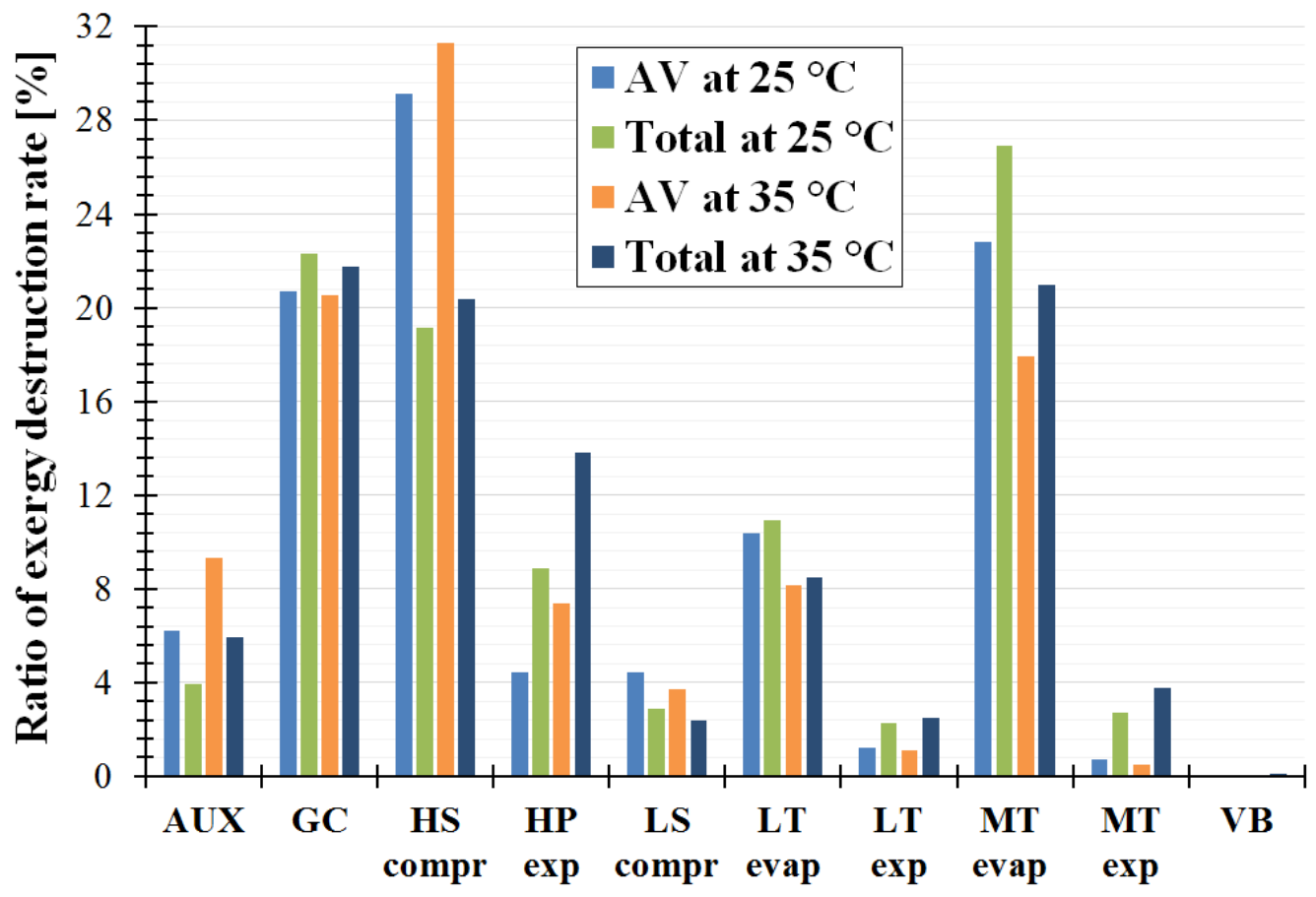

Fig. 4 Ratio of $\dot{\boldsymbol{E}}_{\boldsymbol{D}, \boldsymbol{K}}^{A V}$ to $\dot{\boldsymbol{E}}_{\boldsymbol{D}, \boldsymbol{t} \text { tot }}^{A V}$ and ratio of $\dot{\boldsymbol{E}}_{\boldsymbol{D}, \boldsymbol{k}}$ to $\dot{\boldsymbol{E}}_{\boldsymbol{D}, \boldsymbol{t o t}}$ of the investigated solution at the design outdoor temperatures of $25^{\circ} \mathrm{C}$ and $35^{\circ} \mathrm{C}$. 
Table 11

Advanced exergy parameters of the evaluated system at the design outdoor temperatures of $25^{\circ} \mathrm{C}$.

\begin{tabular}{ccccccccc}
\hline Component & $\dot{\mathrm{E}}_{\mathrm{D}, \mathrm{k}}^{\mathrm{UN}}$ & $\dot{\mathrm{E}}_{\mathrm{D}, \mathrm{k}}^{\mathrm{AV}}$ & $\dot{\mathrm{E}}_{\mathrm{D}, \mathrm{k}}^{\mathrm{EN}}$ & $\dot{\mathrm{E}}_{\mathrm{D}, \mathrm{k}}^{\mathrm{EX}}$ & $\dot{\mathrm{E}}_{\mathrm{D}, \mathrm{k}}^{\mathrm{UN}}$ & $\dot{\mathrm{E}}_{\mathrm{D}, \mathrm{k}}^{\mathrm{UN}, \mathrm{EX}}$ & $\dot{\mathrm{E}}_{\mathrm{D}, \mathrm{k}}^{\mathrm{AV}, \mathrm{kN}}$ & $\dot{\mathrm{E}}_{\mathrm{D}, \mathrm{k}}^{\mathrm{AV}, \mathrm{EX}}$ \\
& {$[\mathrm{kW}]$} & {$[\mathrm{kW}]$} & {$[\mathrm{kW}]$} & {$[\mathrm{kW}]$} & {$[\mathrm{kW}]$} & {$[\mathrm{kW}]$} & {$[\mathrm{kW}]$} & {$[\mathrm{kW}]$} \\
\hline AUX & 0.17 & 2.06 & 1.01 & 1.22 & 0.13 & 0.04 & 0.88 & 1.18 \\
& $(7.7 \%)$ & $(92.3 \%)$ & $(45.3 \%)$ & $(54.7 \%)$ & $(5.9 \%)$ & $(1.8 \%)$ & $(39.4 \%)$ & $(52.9 \%)$ \\
GC & 5.79 & 6.90 & 7.81 & 4.88 & 5.25 & 0.53 & 2.55 & 4.35 \\
HS compr & $(45.6 \%)$ & $(54.4 \%)$ & $(61.5 \%)$ & $(38.5 \%)$ & $(41.4 \%)$ & $(4.2 \%)$ & $(20.1 \%)$ & $(34.3 \%)$ \\
& 1.18 & 9.72 & 8.11 & 2.79 & 1.08 & 0.10 & 7.03 & 2.69 \\
HP exp & $(10.8 \%)$ & $(89.2 \%)$ & $(74.4 \%)$ & $(25.6 \%)$ & $(9.9 \%)$ & $(0.9 \%)$ & $(64.5 \%)$ & $(24.6 \%)$ \\
& 3.58 & 1.48 & 3.22 & 1.84 & 3.22 & 0.36 & 0.00 & 1.48 \\
LS compr & $(70.8 \%)$ & $(29.2 \%)$ & $(63.6 \%)$ & $(36.4 \%)$ & $(63.6 \%)$ & $(7.2 \%)$ & $(0.0 \%)$ & $(29.2 \%)$ \\
& 0.15 & 1.47 & 0.96 & 0.66 & 0.13 & 0.02 & 0.83 & 0.64 \\
LT evap & $(9.2 \%)$ & $(90.8 \%)$ & $(59.3 \%)$ & $(40.7 \%)$ & $(8.0 \%)$ & $(1.3 \%)$ & $(51.4 \%)$ & $(39.4 \%)$ \\
& 2.74 & 3.46 & 6.21 & 0.00 & 2.75 & 0.00 & 3.46 & 0.00 \\
LT exp & $(44.2 \%)$ & $(55.8 \%)$ & $(100.0 \%)$ & $(0.0 \%)$ & $(44.2 \%)$ & $(0.0 \%)$ & $(55.8 \%)$ & $(0.0 \%)$ \\
& 0.89 & 0.40 & 0.78 & 0.51 & 0.78 & 0.11 & 0.00 & 0.40 \\
MT evap & $(69.0 \%)$ & $(31.0 \%)$ & $(60.4 \%)$ & $(39.6 \%)$ & $(60.4 \%)$ & $(8.7 \%)$ & $(0.0 \%)$ & $(31.0 \%)$ \\
& 7.70 & 7.61 & 15.31 & 0.00 & 7.70 & 0.00 & 7.61 & 0.00 \\
MT exp & $(50.3 \%)$ & $(49.7 \%)$ & $(100.0 \%)$ & $(0.0 \%)$ & $(50.3 \%)$ & $(0.0 \%)$ & $(49.7 \%)$ & $(0.0 \%)$ \\
& 1.31 & 0.23 & 1.18 & 0.36 & 1.18 & 0.13 & 0.00 & 0.23 \\
VB & $(85.0 \%)$ & $(15.0 \%)$ & $(76.5 \%)$ & $(23.5 \%)$ & $(76.5 \%)$ & $(8.5 \%)$ & $(0.0 \%)$ & $(15.0 \%)$ \\
& 0.01 & 0.00 & 0.01 & 0.00 & 0.00 & 0.01 & 0.00 & 0.00 \\
Overall system & $(100.0 \%)$ & $(0.0 \%)$ & $(100.0 \%)$ & $(0.0 \%)$ & $(100.0 \%)$ & $(0.0 \%)$ & $(0.0 \%)$ & $(0.0 \%)$ \\
& $(41.4 \%)$ & $(58.6 \%)$ & $(78.4 \%)$ & $(21.6 \%)$ & $(39.1 \%)$ & $(2.3 \%)$ & $(39.3 \%)$ & $(19.3 \%)$ \\
\hline
\end{tabular}


Table 12

Advanced exergy parameters of the evaluated system at the design outdoor temperatures of $35^{\circ} \mathrm{C}$.

\begin{tabular}{ccccccccc}
\hline Component & $\dot{\mathrm{E}}_{\mathrm{D}, \mathrm{k}}^{\mathrm{UN}}$ & $\dot{\mathrm{E}}_{\mathrm{D}, \mathrm{k}}^{\mathrm{AV}}$ & $\dot{\mathrm{E}}_{\mathrm{D}, \mathrm{k}}^{\mathrm{EN}}$ & $\dot{\mathrm{E}}_{\mathrm{D}, \mathrm{k}}^{\mathrm{EX}}$ & $\dot{\mathrm{E}}_{\mathrm{D}, \mathrm{k}}^{\mathrm{UN}, \mathrm{EN}}$ & $\dot{\mathrm{E}}_{\mathrm{D}, \mathrm{k}}^{\mathrm{UN}, \mathrm{EX}}$ & $\dot{\mathrm{E}}_{\mathrm{D}, \mathrm{k}}^{\mathrm{AV}, \mathrm{k}}$ & $\dot{\mathrm{E}}_{\mathrm{D}, \mathrm{k}}^{\mathrm{AV}, \mathrm{EX}}$ \\
& {$[\mathrm{kW}]$} & {$[\mathrm{kW}]$} & {$[\mathrm{kW}]$} & {$[\mathrm{kW}]$} & {$[\mathrm{kW}]$} & {$[\mathrm{kW}]$} & {$[\mathrm{kW}]$} & {$[\mathrm{kW}]$} \\
\hline AUX & 0.36 & 3.97 & 1.81 & 2.51 & 0.26 & 0.10 & 1.55 & 2.42 \\
& $(8.2 \%)$ & $(91.8 \%)$ & $(41.9 \%)$ & $(58.1 \%)$ & $(6.0 \%)$ & $(2.2 \%)$ & $(35.9 \%)$ & $(55.9 \%)$ \\
GC & 7.13 & 8.72 & 8.87 & 6.98 & 6.33 & 0.80 & 2.54 & 6.19 \\
& $(45.0 \%)$ & $(55.0 \%)$ & $(56.0 \%)$ & $(44.0 \%)$ & $(40.0 \%)$ & $(5.0 \%)$ & $(16.0 \%)$ & $(39.0 \%)$ \\
HS compr & 1.57 & 13.29 & 11.30 & 3.56 & 1.41 & 0.16 & 9.89 & 3.40 \\
& $(10.6 \%)$ & $(89.4 \%)$ & $(76.0 \%)$ & $(24.0 \%)$ & $(9.5 \%)$ & $(1.1 \%)$ & $(66.6 \%)$ & $(22.9 \%)$ \\
HP exp & 6.93 & 3.13 & 6.13 & 3.93 & 6.13 & 0.80 & 0.00 & 3.13 \\
& $(68.8 \%)$ & $(31.2 \%)$ & $(60.9 \%)$ & $(39.1 \%)$ & $(60.9 \%)$ & $(8.0 \%)$ & $(0.0 \%)$ & $(31.2 \%)$ \\
LS compr & 0.16 & 1.59 & 1.03 & 0.72 & 0.14 & 0.03 & 0.89 & 0.70 \\
& $(9.3 \%)$ & $(90.7 \%)$ & $(58.6 \%)$ & $(41.4 \%)$ & $(7.9 \%)$ & $(1.5 \%)$ & $(50.8 \%)$ & $(39.9 \%)$ \\
LT evap & 2.74 & 3.46 & 6.21 & 0.00 & 2.74 & 0.00 & 3.46 & 0.00 \\
& $(44.2 \%)$ & $(55.8 \%)$ & $(100.0 \%)$ & $(0.0 \%)$ & $(44.2 \%)$ & $(0.0 \%)$ & $(55.8 \%)$ & $(0.0 \%)$ \\
LT exp & 1.33 & 0.47 & 1.15 & 0.66 & 1.15 & 0.18 & 0.00 & 0.47 \\
& $(73.8 \%)$ & $(26.3 \%)$ & $(63.7 \%)$ & $(36.3 \%)$ & $(63.7 \%)$ & $(10.1 \%)$ & $(0.0 \%)$ & $(26.3 \%)$ \\
MT evap & 7.69 & 7.61 & 15.30 & 0.00 & 7.70 & 0.00 & 7.61 & 0.00 \\
& $(50.3 \%)$ & $(49.7 \%)$ & $(100.0 \%)$ & $(0.0 \%)$ & $(50.3 \%)$ & $(0.0 \%)$ & $(49.7 \%)$ & $(0.0 \%)$ \\
MT exp & 2.51 & 0.22 & 2.24 & 0.49 & 2.24 & 0.27 & 0.00 & 0.22 \\
& $(92.0 \%)$ & $(8.0 \%)$ & $(82.0 \%)$ & $(18.0 \%)$ & $(82.0 \%)$ & $(10.0 \%)$ & $(0.0 \%)$ & $(8.0 \%)$ \\
VB & 0.03 & 0.03 & 0.03 & 0.03 & 0.03 & 0.00 & 0.00 & 0.03 \\
& $(50.0 \%)$ & $(50.0 \%)$ & $(50.0 \%)$ & $(50.0 \%)$ & $(50.0 \%)$ & $(0.0 \%)$ & $(0.0 \%)$ & $(50.0 \%)$ \\
& 30.46 & 42.49 & 54.06 & 18.90 & 28.12 & 2.35 & 25.94 & 16.55 \\
& $(41.7 \%)$ & $(58.3 \%)$ & $(74.1 \%)$ & $(25.9 \%)$ & $(38.5 \%)$ & $(3.2 \%)$ & $(35.6 \%)$ & $(22.7 \%)$ \\
\hline
\end{tabular}




\subsubsection{Endogenous and exogenous exergy destruction}

The irreversibilities occurring in the investigated system were mainly endogenous and, in particular, $\dot{E}_{D, t o t}^{E N}$ was equal to $78.4 \%$ at $25^{\circ} \mathrm{C}$ and to $74.1 \%$ at $35^{\circ} \mathrm{C}$ of $\dot{E}_{D}$, respectively. As a main consequence of this result, its enhancement could mainly be accomplished by dropping the inefficiencies of the components themselves.

As previously proved by Chen et al. (2015), Morosuk et al. (2012) and Morosuk and Tsatsaronis (2009), the exergy destruction rate of both the evaporators was completely endogenous independently of the external temperature. The auxiliary compressor was the only component which showed slightly greater exogenous exergy destruction rates than endogenous ones. The contribution to the total endogenous exergy rate associated with AUX, HS compr, HP exp, MT exp and LT exp enlarged as the outdoor temperature went up. Unlike them, that related to the remaining components was increasing in terms of absolute value and decreasing in relation to percentage.

\subsubsection{Avoidable endogenous and exogenous exergy destruction}

The total preventable exergy destruction rates of the evaluated system could chiefly be reduced by bringing down the inefficiencies taking place in its components. The increment in the design temperature led to a lower influence of the interactions among the components since $\dot{E}_{D, t o t}^{A V, E N}$ added up to $67.1 \%$ at text $=25^{\circ} \mathrm{C}$ and to $61.1 \%$ at text $=35^{\circ} \mathrm{C}$ of $\dot{E}_{D, \text { tot }}^{A V}$ (Fig. 3a and Fig. 3b).

At the design temperature of $25^{\circ} \mathrm{C}$, the avoidable exergy destruction rates associated with both the evaporators were completely endogenous (Chen et al., 2015; Morosuk et al., 2012; Morosuk and Tsatsaronis, 2009), whereas the ones of the expansion valves had null values of $\dot{E}_{D}^{A V, E N}$. The large amount of the avoidable irreversibilities of HS compr could be principally avoided by replacing it with a more efficient component. The values of $\dot{E}_{D}^{A V, E X}$ of AUX, GC and LS compr were respectively equal to $57.3 \%, 63.0 \%$ and $43.4 \%$ of their related total preventable exergy destruction rates.

The observations associated with the outcomes computed at $25{ }^{\circ} \mathrm{C}$ could be extended to those computed at $35^{\circ} \mathrm{C}$. Furthermore, $\dot{E}_{D, g c}^{A V, E X}$ calculated at $35^{\circ} \mathrm{C}$ underwent an increase by $42.2 \%$ in comparison with that calculated at $25^{\circ} \mathrm{C}$, whereas $\dot{E}_{D, a u x}^{A V, E X}$ almost doubled. The increment of $\dot{E}_{D, \text { aux }}^{A V, E N}$ and $\dot{E}_{D, H P \exp }^{A V, E X}$ due to the growth in the outdoor temperature were equal to $76.5 \%$ and $112.2 \%$, respectively.

\subsubsection{Interactions among components}

The effect of the system under investigation on the component being taken into account are revealed by evaluating its mexogenous exergy destruction.

At both the chosen design temperatures, the improvement of AUX could be reached by reducing the irreversibilities due to the simultaneous interactions among the components. $\dot{E}_{D, \text { aux }}^{E X, g c}$ and $\dot{E}_{D, \text { aux }}^{M X}$ underwent a doubling because of the increment in the external temperature. As for GC, it was substantially influenced by MT evap and, secondly, by HS compr. On the other hand, GC was accountable for the improvement of HP exp, especially at high external temperatures. Furthermore, the negative value of $\dot{E}_{D, g c}^{M X}$ pointed out the need for increasing the irreversibilities of the investigated system in order to lower the ones associated with the gas cooler. The latter outcome was relevantly marked at text $=35^{\circ} \mathrm{C} . \dot{E}_{D, g c}^{E X, H S c o m p r}$ and $\dot{E}_{D, g c}^{E X, M T e v a p}$ indicated a growth as a consequence of the increment in the design temperature respectively by 1.4 times and 2.2 times in comparison with the related values calculated at $25^{\circ} \mathrm{C}$. Additionally, $\dot{E}_{D, M T \exp }^{M X}$ was slightly negative at text $=35^{\circ} \mathrm{C}$. 
Table 13

Mexogenous exergy parameters of the system under investigation at the design outdoor temperatures of 25 and $35^{\circ} \mathrm{C}$.

\begin{tabular}{|c|c|c|c|c|}
\hline \multirow{2}{*}{$\frac{\dot{\mathbf{E}}_{\mathbf{D}, \mathbf{k}}^{\mathrm{EX}}[\mathrm{kW}]}{\mathrm{AUX}}$} & \multicolumn{2}{|c|}{$\dot{\mathrm{E}}_{\mathrm{D}, \mathrm{k}}^{\mathrm{EX}, \mathrm{r}}[\mathrm{kW}]$ at $\mathrm{t}_{\mathrm{ext}}=25^{\circ} \mathrm{C}$} & \multicolumn{2}{|c|}{$\dot{\mathrm{E}}_{\mathrm{D}, \mathrm{k}}^{\mathrm{EX}, \mathrm{r}}[\mathrm{kW}]$ at $\mathrm{t}_{\mathrm{ext}}=35^{\circ} \mathrm{C}$} \\
\hline & GC & 0.34 & GC & 0.71 \\
\hline \multirow[t]{2}{*}{1.22 at $25^{\circ} \mathrm{C}$} & HP exp & 0.15 & HP exp & 0.37 \\
\hline & LT evap & 0.03 & LT evap & 0.06 \\
\hline \multirow[t]{4}{*}{2.51 at $35^{\circ} \mathrm{C}$} & LT exp & 0.01 & LT exp & 0.01 \\
\hline & MT evap & 0.08 & MT evap & 0.14 \\
\hline & MT exp & 0.01 & MT exp & 0.03 \\
\hline & MX & 0.61 & MX & 1.19 \\
\hline GC & $\overline{A U X}$ & 0.15 & AUX & 0.29 \\
\hline \multirow[t]{2}{*}{4.88 at $25^{\circ} \mathrm{C}$} & HS compr & 1.08 & HS compr & 1.56 \\
\hline & HP exp & 0.04 & HP exp & 0.11 \\
\hline \multirow[t]{6}{*}{6.98 at $35^{\circ} \mathrm{C}$} & LS compr & 0.12 & LS compr & 0.14 \\
\hline & LT evap & -2.90 & LT evap & -4.55 \\
\hline & $\mathrm{LT}$ exp & 0.03 & $\mathrm{LT}$ exp & 0.05 \\
\hline & MT evap & 20.70 & MT evap & 44.79 \\
\hline & MT exp & 0.04 & MT exp & 0.09 \\
\hline & MX & -14.38 & MX & -35.50 \\
\hline HS compr & $\overline{G C}$ & 0.00 & GC & 0.01 \\
\hline \multirow{2}{*}{2.79 at $25^{\circ} \mathrm{C}$} & HP exp & 0.00 & HP exp & 0.01 \\
\hline & LS compr & 0.06 & LS compr & 0.08 \\
\hline \multirow[t]{6}{*}{3.56 at $35^{\circ} \mathrm{C}$} & LT evap & 0.36 & LT evap & 0.50 \\
\hline & LT exp & 1.91 & LT exp & 3.46 \\
\hline & MT evap & 2.08 & MT evap & 2.48 \\
\hline & MT exp & 0.07 & MT exp & 0.20 \\
\hline & $\mathrm{VB}$ & 0.00 & $\mathrm{VB}$ & 0.01 \\
\hline & MX & -1.69 & MX & -3.19 \\
\hline HP exp & GC & 0.68 & GC & 1.77 \\
\hline \multirow{2}{*}{1.84 at $25^{\circ} \mathrm{C}$} & LT evap & 0.10 & LT evap & 0.19 \\
\hline & LT exp & 0.02 & LT exp & 0.05 \\
\hline \multirow[t]{3}{*}{3.93 at $35^{\circ} \mathrm{C}$} & MT evap & 0.25 & MT evap & 0.47 \\
\hline & MT exp & 0.03 & MT exp & 0.11 \\
\hline & MX & 0.76 & MX & 1.35 \\
\hline MT exp & AUX & 0.00 & AUX & 0.01 \\
\hline \multirow[t]{2}{*}{0.36 at $25^{\circ} \mathrm{C}$} & GC & 0.00 & GC & 0.01 \\
\hline & HS compr & 0.00 & HS compr & 0.01 \\
\hline \multirow[t]{7}{*}{0.49 at $35^{\circ} \mathrm{C}$} & HP exp & 0.00 & HP exp & 0.01 \\
\hline & LS compr & 0.00 & LS compr & 0.01 \\
\hline & LT evap & 0.00 & LT evap & 0.01 \\
\hline & LT exp & 0.00 & LT exp & 0.01 \\
\hline & MT evap & 0.36 & MT evap & 0.49 \\
\hline & VB & 0.00 & $\mathrm{VB}$ & 0.01 \\
\hline & $\mathrm{MX}$ & 0.00 & MX & -0.11 \\
\hline
\end{tabular}




\section{Discussion}

According to the outcomes related to the conventional exergy analysis, the gas cooler/condenser (12.69-15.85 kW), the high stage compressor (10.90-14.86 kW) and the MT display cabinet (15.31 $\mathrm{kW})$ are accountable for the highest irreversibilities taking place in the system under investigation. The exergy destruction rates associated with the high pressure expansion valve and the LT evaporator are also significant at both the evaluated design temperatures. In particular, $\dot{E}_{D, H P \exp }$ outweighs as the external temperature goes up, whereas $\dot{E}_{D, L T e v a p}$ undergoes the opposite trend (in percentage).

At both the selected operating conditions, the chosen system presents slightly higher avoidable exergy destruction rates than unavoidable ones and larger irreversibilities occurring in the components in comparison with those due to the interactions among the components. The high stage compressor exhibits a high enhancement potential since $\dot{E}_{D, H S c o m p r}^{A V}$ adds up to over $89 \%$ of $\dot{E}_{D, H S c o m p r}$. Only half of the inefficiencies occurring in the MT evaporator and in the gas cooler/condenser can actually be avoided. Such result can be also extended to the LT evaporator. Furthermore, the contribution of the auxiliary compressor to the total avoidable exergy destruction is equal to $6.2 \%$ at $25{ }^{\circ} \mathrm{C}$ and $9.3 \%$ at $35^{\circ} \mathrm{C}$.

The increase in the design temperature entails a slight reduction in the influence of the interactions among the components on the total irreversibilities. In fact, the total preventable endogenous exergy destruction is approximately $67 \%$ at $25^{\circ} \mathrm{C}$ and $61 \%$ at $35^{\circ} \mathrm{C}$ of the total endogenous avoidable exergy destruction. $\dot{E}_{D}^{A V, E N}$ is the most considerable part of the avoidable exergy destruction related to the high stage compressor. The avoidable irreversibilities associated with both the auxiliary compressor and the gas cooler/condenser are mainly exogenous, especially at high outdoor temperatures. An amount of inefficiencies at least equal to 57.3\% related to AUX can be decreased through the improvement of the remaining components and, in particular, through the enhancement of GC. A reduction in $\Delta \mathrm{T}_{\mathrm{appr}, \mathrm{gc}}$, in fact, would allow lowering the pressure ratio of the auxiliary compressor and, accordingly, its inefficiencies. Although the preventable irreversibilities occurring in HS compr can mainly be lessened by improving the component itself, additional benefits can be accomplished by reducing the approach temperature of the MT evaporator. In fact, this would permit decreasing the pressure ratio of HS compr and, consequently, the exergy destruction rate associated with such component. Additionally, the higher the design outdoor temperature, the more beneficial an increase in the medium evaporating temperature would be. The reason for this result lies in the fact that the adoption of the latter expedient would entail a reduction in the discharge temperatures of both HS compr and AUX. The latter tends to have higher values of optimum intermediate pressure as the evaporating temperature rises. As a consequence of this, the amount of heat rejected through the high pressure heat exchanger and thus the irreversibilities related to GC would drop.

\section{Conclusions}

Although relevant enhancements are still necessary for R744 refrigeration systems operating in warm weathers, the interest in carbon dioxide as a refrigerant has been growing rapidly in the last few years. In this paper, the thermodynamic performance of a commercial $\mathrm{CO}_{2}$ refrigerating plant with parallel compression has been evaluated through the application of the advanced exergy analysis. Such configuration represents one of the most promising technologies to be employed in the near future. The design outdoor temperatures of $25^{\circ} \mathrm{C}$ and $35^{\circ} \mathrm{C}$ have been considered in order to evaluate both a transition operating condition (from subcritical to transcritical operations) and a transcritical one. The running modes of a typical European supermarket have been selected, whereas the global efficiencies of all the compressors have been obtained by means of some data provided from some manufacturers' selection software. Appropriate optimization procedures have been implemented in all the conducted analyses using the flash gas mass flow rate drawn by the auxiliary compressor $(\chi)$ and the intermediate pressure as independent variables in the evaluated transition running mode. The 
optimal gas cooler pressure has been utilized as an additional optimization input parameter in the chosen transcritical operating mode. Such value has been calculated in actual conditions and then kept constant during all the performed evaluations.

According to the outcomes obtained in this study, it can be concluded that the only application of the conventional exergy analysis would have driven to some misleading results. The auxiliary compressor, in fact, is chiefly improvable by bringing down the irreversibilities of the remaining components, especially the ones associate with the gas cooler/condenser. On the other hand, the latter can be mainly enhanced by reducing the approach temperature of the MT evaporator. The adoption of such measure would allow also decreasing the inefficiencies of the high stage compressor.

The following concluding remarks can thus be claimed:

- the advanced exergy analysis leads to a better understanding of the design procedure to be applied to the investigated solution;

- the total avoidable exergy destruction of the studied system is slightly greater than the total unavoidable one at both the selected design temperatures;

- the interaction among the components, except for the gas cooler/condenser, is weak.

\section{Acknowledgments}

Paride Gullo would like to thank the "Fondo Sociale Europeo in Friuli Venezia Giulia" for the economic support to the present research.

\section{References}

- Açikkalp, E., Aras, H., Hepbasli, A., 2014. Advanced exergy analysis of a trigeneration system with a diesel-gas engine operating in a refrigerator plant building. Energy and Buildings 80, 268275. DOI: $10.1016 /$ j.enbuild.2014.05.029

- Bell, I., 2004. Performance increase of carbon dioxide refrigeration cycle with the addition of parallel compression economization. In: Proceedings of the $6^{\text {th }}$ IIR Gustav Lorentzen Conference on Natural Refrigerants; Glasgow, United Kingdom.

- BITZER, 2015. BITZER Software Version 6.4.3.1302 - Available at: $<$ https://www.bitzer.de/websoftware/> [accessed 30.12.2015].

- Cavallini, A., Zilio, C., 2007. Carbon dioxide as a natural refrigerant. International Journal of Low-Carbon Technologies 2(3), 225-249. DOI: $10.1093 / \mathrm{ij} l \mathrm{lct} / 2.3 .225$

- Chen, J., Havtun, H., Björn, P., 2015. Conventional and advanced exergy analysis of an ejector refrigeration system. Applied Energy 144, 139-151. DOI: $\underline{\text { 10.1016/j.apenergy.2015.01.139 }}$

- Chiarello, M., Girotto, S., Minetto, S., 2010. $\mathrm{CO}_{2}$ supermarket refrigeration system for hot climates. In: Proceedings of the $9^{\text {th }}$ IIR-Gustav Lorentzen Conference on Natural Refrigerants; Sydney, Australia.

- Erbay, Z., Hepbasli, A., 2014. Application of conventional and advanced exergy analyses to evaluate the performance of a ground-source heat pump (GSHP) dryer used in food drying. Energy Conversion and Management 78, 499-507. DOI: $\underline{10.1016 / j . e n c o n m a n .2013 .11 .009}$

- F-Chart Software, 2015a. Engineering Equation Solver (EES), Academic Professional version 9.908 - Available at: <http://www.fchart.com/ees/> [accessed 30.12.2015].

- F-Chart Software, 2015b. Engineering Equation Solver Manual, Madison (USA) - Available at: <http://www.fchart.com/assets/downloads/ees_manual.pdf $>$ [accessed 30.12.2015]. 
- Fazelpour, F., Morosuk, T., 2014. Exergoeconomic analysis of carbon dioxide transcritical refrigeration machines. International Journal of Refrigeration 38, 128-139. DOI: 10.1016/j.ijrefrig.2013.09.016

- Ge, Y.T., Tassou, S.A., 2011. Thermodynamic analysis of transcritical $\mathrm{CO}_{2}$ booster refrigeration systems in supermarket. Energy Conversion and Management 52(4), 1868-1875. DOI: 10.1016/j.enconman.2010.11.015

- Gullo, P., Elmegaard, B., Cortella, G., 2016. Energy and environmental performance assessment of R744 booster supermarket refrigeration systems operating in warm climates. International Journal of Refrigeration 64, 61-79. DOI: 10.1016/j.ijrefrig.2015.12.016

- Gullo, P., Elmegaard, B., Cortella, G., 2015. Energetic, Exergetic and Exergoeconomic Analysis of $\mathrm{CO}_{2}$ Refrigeration Systems Operating in Hot Climates. In: Proceedings of the $28^{\text {th }}$ International Conference on Efficiency, Cost, Optimization Simulation and Environmental Impact of Energy Systems; Pau, France.

- Gungor, A., Erbay, Z., Hepbasli, A., Gunerhan, H., 2013. Splitting the exergy destruction into avoidable and unavoidable parts of a gas engine heat pump (GEHP) for food drying processes based on experimental values. Energy Conversion and Management 73, 309-316. DOI: $\underline{10.1016 / j . e n c o n m a n .2013 .04 .033 ~}$

- Minetto, S., Cecchinato, L., Corradi, M., Fornasieri, E., Zilio, C., 2005. Theoretical and Experimental Analysis of a $\mathrm{CO}_{2}$ Refrigerating Cycle with Two-Stage Throttling and Suction of the Flash Vapour by an Auxiliary Compressor. In: Proceedings of IIR International Conferences - Thermophysical Properties and Transfer Processes of Refrigerants; Vicenza, Italy.

- Moran, M.J., Shapiro, H.N., Boettner, D.D., Bailey, M.B., 2011. Fundamentals of Engineering Thermodynamics. New York: John Wiley \& Sons.

- Morosuk, T., Tsatsaronis, G., Zhang, C., 2012. Conventional thermodynamic and advanced exergetic analysis of a refrigeration machine using a Voorhees' compression process. Energy Conversion and Management 60, 143-151. DOI: 10.1016/j.enconman.2012.02.021

- Morosuk, T., Tsatsaronis, G., 2009. Advanced exergetic evaluation of refrigeration machines using different working fluids. Energy 34(12), 2248-2258. DOI: 10.1016/j.energy.2009.01.006

- Ommen, T., Elmegaard, B., 2012. Numerical model for thermoeconomic diagnosis in commercial transcritical/subcritical booster refrigeration systems. Energy Conversion and Management 60, 161-169. DOI: 10.1016/j.enconman.2011.12.028

- Polzot, A., D’Agaro, P., Gullo, P., Cortella, G., 2015. Water storage to improve the efficiency of $\mathrm{CO}_{2}$ commercial refrigeration systems. In: Proceedings of the $24^{\text {th }}$ IIR International Congress of Refrigeration - ICR 2015; Yokohama, Japan.

- Sarkar, J., Agrawal, N., 2010. Performance optimization of transcritical $\mathrm{CO}_{2}$ cycle with parallel compression economization. International Journal of Thermal Sciences 49(5), 838-843. DOI: 10.1016/j.ijthermalsci.2009.12.001

- Sawalha, S., 2008. Theoretical evaluation of trans-critical $\mathrm{CO}_{2}$ systems in supermarket refrigeration. Part I: Modeling, simulation and optimization of two system solutions. International Journal of Refrigeration 31(3), 516-524. DOI: 10.1016/j.ijrefrig.2007.05.017

- Tsatsaronis, G., 2008. Recent developments in exergy analysis and exergoeconomics. International Journal of Exergy 5(5/6), 489-499. DOI: 10.1504/IJEX.2008.020822

- Tsatsaronis, G., Moung-Ho, P., 2002. On avoidable and unavoidable exergy destructions and investment costs in thermal systems. Energy Conversion and Management 43(9-12), 1259-1270. DOI: 10.1016/S0196-8904(02)00012-2

- Wang, L., Yang, Y., Morosuk, T., Tsatsaronis, G., 2012. Advanced Thermodynamic Analysis and Evaluation of a Supercritical Power Plant. Energies 5(6), 1850-1863. DOI: $\underline{10.3390 / \text { en5061850 }}$ 